\title{
LA IDEA DE UNIVERSIDAD EN NEWMAN Y BENEDICTO XVI
}

\section{THE IDEA OF UNIVERSITY IN NEWMAN AND BENEDICT XVI}

\author{
FERNANDO VIÑADO OTEO \\ Universidad Francisco de Vitoria, España \\ Ángel BARAHONA PlazA \\ Universidad Francisco de Vitoria, España
}

Recibido: 17/01/2020 Aceptado: 24/06/2020

\section{RESUMEN}

En el presente artículo abordamos la confluencia de Newman y Benedicto XVI acerca de la cuestión del sentido en la Universidad. Fruto de un pormenorizado estudio de los textos de los autores, analizamos cinco puntos esenciales que desvelan la idea de Universidad de ambos autores: la pasión por la verdad, el necesario diálogo entre fe y razón, la conciencia como santuario de la persona y su libertad, el testimonio vital de la verdad y la especial pedagogía que supone dar testimonio de la amable luz interior.

Palabras clave: Universidad, Benedicto XVI, Newman, Verdad, Fe y razón, Pedagogía del testimonio

\section{ABSTRACT}

In this article, we address the confluence of Newman and Benedict XVI about the question of meaning in the University. The result of a detailed study of the texts of the 
authors, we analyze five essential points that reveal the idea of University of both authors: the passion for truth, the necessary dialogue between faith and reason, conscience as a sanctuary of the person and freedom, the vital testimony of the truth and the special pedagogy of witnessing the kind interior light.

Keywords: University, Benedict XVI, Newman, Truth, Faith and Reason, Testimony Pedagogy

\section{INTRODUCCIÓN}

A lo largo del presente artículo desgranamos los principales puntos de confluencia de Newman y Benedicto XVI acerca de la cuestión del sentido en la Universidad. Tras un análisis de los textos de Ratzinger/Benedicto XVI confirmamos la notable influencia que Newman ejerció en su pensamiento y a la par la confluencia en su idea de Universidad. La pasión por la verdad, el necesario diálogo entre fe y razón, la conciencia como santuario de la persona y su libertad, el testimonio vital de la verdad, su lema cardenalicio y la especial pedagogía que supone dar testimonio de la amable luz interior, son los puntos que estimamos más relevantes. Por otra parte, la doctrina de Newman ha sido determinante en la configuración de la imagen del hombre, el concepto de Iglesia y la libertad de conciencia en el primado del papa ${ }^{1}$. La lucha de Newman "contra la creciente tendencia a percibir la religión como un asunto puramente privado y subjetivo, una cuestión de opinión personal"² es lección para aprender.

1 En referencia al discurso pronunciado con motivo del centenario de la muerte de Newman, afirmará: "La dottrina di Newman sulla coscienza divenne allora per noi il fondamento di quel personalismo teologico, che ci attrasse tutti col suo fascino. La nostra immagine dell'uomo, così come la nostra concezione della Chiesa, furono segnate da questo punto di partenza. [...]Da Newman abbiamo imparato a comprendere il primato del Papa: la libertà di coscienza [...] Questa dottrina sulla coscienza è diventata per me sempre più importante nello sviluppo successivo della Chiesa e del mondo" Joseph Ratzinger, Discorso del Card. Ratzinger nel centenario della morte del Card. John H. Newman (Roma: Archivio della Congregazione per la Dottrina della Fede (novembre 1981-aprile 2005), 1990), http://www.vatican.va/roman_curia/congregations/cfaith/docu-

ments/rc_con_cfaith_doc_199000428_ratzinger-newman_it.html.. Una traducción del mismo se encuentra en: Joseph Ratzinger, "Presentación a cargo de su eminencia el cardenal Joseph Ratzinger con ocasión del primer centenario de la muerte del cardenal John Henry Newman, Roma, 28 de abril de 1990", en Apologia pro vita sua. Historia de mis ideas religiosas, trad. Federico de Carlos Otto (Madrid: Ciudadela Libros, 2009), 9-14, http://www.vatican.va/roman_curia/congregations/cfaith/documents/rc_co n_cfaith_doc_19900428_ratzinger-newman_en.html.

2 Benedicto XVI, Saludo en la Vigilia de oración por la beatificación del cardenal John Henry Newman en Hyde Park. Londres, 18/09/2010. 


\section{METODOLOGÍA}

Hemos analizado y clasificado todas las intervenciones y escritos de Benedicto XVI en los que expresamente cita o hace referencia a John Henry Newman. De su estudio se desprende la influencia que Newman tuvo en Benedicto XVI. Uno de sus profesores de sus años de formación, su Doktorvater, Gottlieb Söhngen, gran conocedor de Newman ${ }^{3}$, imprimirá un especial carácter en el joven Ratzinger acerca de la pasión por la verdad, la constante preocupación por el debate filosófico y el rigor en el acercamiento a las fuentes originarias. A su vez hemos estudiado los textos de Newman extrayendo aquellos puntos de confluencia con la idea de universidad de Benedicto XVI.

En el presente artículo solo incluimos las tesis principales dejando de lado el análisis particular de cada uno de los textos. En un intento de ser fieles al pensamiento del Papa emérito, hemos intentado, siempre que nos ha sido posible, expresar las ideas con sus mismas palabras citando, de este modo, un buen número de sus textos e intervenciones.

\section{LA CUESTION DE SENTIDO EN LA UNIVERSIDAD A LA LUZ DEL PENSAMIENTO DE NEWMAN Y BENEDICTO XVI}

\section{PASIÓN POR LA VERDAD}

Newman busca la verdad y esta búsqueda se convierte en el motor de su vida y en la respuesta a la pregunta por el sentido, no sin dificultades y sombras, frente al subjetivismo de la iglesia anglicana que reinventa su raíz, el deterioro de una sociedad bajo el yugo de la reforma liberal, secular y progresista y el ideal de Oxford que aspiraba a reconstruir los valores espirituales y religiosos. Newman, de la mano de Froude (y éste a su vez de Keble), era consciente de todo ello y de que si en algún lugar se podía iniciar una segunda Reforma era en la universidad, espacio natural de los movimientos de ideas ${ }^{4}$.

En un ejercicio de verdadera búsqueda de la verdad como algo objetivo y cognoscible por la razón, de restaurar la fe apostólica y alejarla de sus humanos

3 "Gottlieb, il mio vero maestro in teologia, un colto e appassionato seguace di Newman" Así lo describirá siendo prefecto de la Congregación para la Doctrina de la Fe en su discurso con motivo del centenario de la muerte del cardenal Newman. Cfr. Ratzinger, Discorso del Card. Ratzinger nel centenario della morte del Card. John H. Newman.

4 Cfr. Christopher Dawson, El espíritu del movimiento de Oxford, trad. José Morales (Madrid: Rialp, 2000), 103-5. 
errores y en especial de la tutela del Estado, se publican los Tracts for the Times. Sin embargo, no fueron así entendidos ni tampoco supusieron una "segunda Reforma"; más aún, de todos los lugares recibieron él y sus seguidores, críticas y acusaciones de promover el influjo del catolicismo. Es ante esta realidad que, durante los tres siguientes años, Newman se dedica a su obra The Prophetical Office of the Church, Viewed Relatively to Romanism and Popular Protestantism. En su Apología, comentará acerca del mismo:

"Existía además otro motivo para este libro, ya más personal, que debo mencionar. Me parecía una cobardía intelectual no encontrar en la razón una base para mis creencias, y una cobardía moral no declarar públicamente esa base. No me habría sentido hombre de una pieza si no la expresaba, cualquiera que fuese" 5 .

Esta misma pasión por la verdad en coherencia con la vida, y la no aceptación del anglicanismo y de Oxford, hará que deje de ejercer las funciones clericales y se retire a someter sus dudas a la crítica. $\mathrm{Y}$ así fue su vida: un constante peregrinar, no pocas veces desde la soledad y el creerse abandonado por los hombres ${ }^{6}$.

El profesor García Ruiz trae una cita de una carta escrita a una conversa datada en 1861, con sesenta años de edad, donde manifiesta su sensación de fracaso:

"He procurado servir a Dios año tras año, durante treinta; y en tanto que eran obras de servicio, todas han fallado. Mi primer sermón anglicano fue sobre el texto "El hombre va a su labor y a su trabajo hasta la noche"; ahora la noche llega para mí y no he hecho nada. Me acuerdo de esos versos de Keble: "Sobre el fracaso Tú, Señor, puedes enviar tu bendición, etc.”. Sé que es mejor para mí este no haber hecho nada y, no obstante, es duro seguir trabajando a la vista de treinta años de fracasos. Así es. Todo se me queda en nada entre las manos, como si trenzara maromas de arena"'

5 John Henry Newman, Apologia pro vita sua: historia de mis ideas religiosas, trad. Victor García Ruiz y José Morales, Edición conmemorativa (Madrid: Ediciones Encuentro, S.A., 2019), 125.

6 Mónica Georgina Luque, La idea de universidad: estudios sobre Newman, Ortega y Gasset y Jaspers (Washington: INTERAMER. Serie educativa, 1993), cap.2, 3.

7 Víctor García Ruíz, “«Cor ad cor loquitur». El poderoso lenguaje de John Henry Newman”, Scripta Theologica - Universidad de Navarra 33 (febrero de 2001): 448. Victor García Ruiz pertenece al Departamento de Literatura hispánica de la Universidad de Navarra y uno de los mejores y más acertados traductores de Newman 
Dos de sus grandes obras, Perder y Ganar $^{8}$ y Apología pro vita sua ${ }^{9}$ son escritas como respuesta a aquellos momentos de sombra y ante la necesidad de poder mostrar la luz de la Verdad que él ha encontrado ${ }^{10}$. Benedicto XVI dirá que las tres notas que le caracterizan son su honradez en la búsqueda de la verdad, la fidelidad a los dictados de la conciencia y su resolución hacia el ideal de santidad $^{11}$. Tres acentos que podemos acopiar para nuestro modo de acercarnos a la pregunta por el sentido en la universidad.

Benedicto XVI advirtió e hizo suyo este movimiento: pasión por la verdad, honestidad y coherencia y testimonio vital. Así lo expresó en la Vigilia de Oración anterior a la Beatificación:

"La vida de Newman nos enseña también que la pasión por la verdad, la honestidad intelectual y la auténtica conversión son costosas. No podemos guardar para nosotros mismos la verdad que nos hace libres; hay que dar testimonio de ella, que pide ser escuchada, y al final su poder de convicción proviene de sí misma y no de la elocuencia humana o de los argumentos que la expongan"12.

La conversión de Newman fue "religiosa e intelectual", dirá también el Papa en esa Vigilia ${ }^{13}$. No es casualidad que el lema episcopal elegido por Ratzinger cuando el 25 de marzo de 1977 Pablo VI le nombró arzobispo de Múnich fuera "Colaborador de la Verdad"14. Verdad, honestidad, intelectual, testimonio y coherencia serán pilares de su idea de universidad. Comprender la tensión de la Verdad que nos demanda es la respuesta a la cuestión del sentido.

8 John Henry Newman, Perder y ganar, trad. Victor García Ruiz (Madrid: Encuentro, 2017).

9 Newman, Apologia pro vita sua.

10 Victor García Ruiz, en una nota introductoria a la edición de Perder y Ganar, comenta: "Loss and gain, escrita entre risas, fue un testimonio palpitante de una opción moral, como lo volvería a ser después, con acentos más dramáticos, la Apología, escrita entre sollozos y la extenuación física" Newman, Perder y ganar, 19.

11 "En efecto, Newman, ya sea como anglicano que como católico, tuvo que sufrir muchas pruebas, decepciones e incomprensiones. Sin embargo, nunca se rebajó a falsas componendas ni se contentó con fáciles consensos. Siguió siendo siempre honrado en la búsqueda de la verdad, fiel a los dictados de su conciencia y resuelto hacia el ideal de la santidad" Benedicto XVI, Mensaje con ocasión del Simposio organizado por el Centro Internacional Amigos de Newman, 18/11/2010.

12 Benedicto XVI, Saludo en la Vigilia de oración por la beatificación del cardenal John Henry Newman en Hyde Park. Londres, 18/09/2010

13 Ibid.

14 Mitarbeiter der Wahrheit (Colaboradores de la Verdad)], "ante todo -afirma Benedicto XVIporque me parecía que podían representar bien la continuidad entre mi tarea anterior y el nuevo cargo; porque, con todas las diferencias que se quieran, se trataba y se trata siempre de lo mismo: seguir la verdad, ponerse a su servicio". Joseph Ratzinger, Mi vida: recuerdos 1927-1977, trad. Carlos d'Ors Führer, 2.a ed. (Madrid: Ediciones Encuentro, 2006), 183. 


\section{FE Y RAZÓN EN LA UNIVERSIDAD}

Frente a los enfoques reductivos o utilitaristas, frente al subjetivismo que todo lo inunda y que han provocado esta "emergencia educativa", Benedicto XVI propone ensanchar los horizontes de la racionalidad y abrirse al encuentro y el diálogo de la fe y la razón. Esta idea le acompañará toda su vida y marcará todos sus discursos en los que trate sobre la universidad. Esa intuición, sin duda, es heredera de su lectura de Newman.

Newman, en su conferencia sobre "Cristianismo e investigación científica", una y otra vez reclamaba la necesidad de ese encuentro entre las ciencias y la fe siendo la universidad mucho más que un espacio donde se alojan y acogen ${ }^{15}$. Como dicen Miguel Ángel Martín y Jorge Cáceres, citando a Newman, al conocimiento científico hay que aproximarse por grados, pero no obtendríamos una visión integral, que convirtiese el conocimiento en sabiduría, excluyendo la teología.

"De esta forma el conocimiento que el individuo puede desarrollar, es decir, el intelecto, es el aprendizaje de esos hechos y esas relaciones. Sin embargo, estos últimos son difíciles de abordar con un simple acercamiento. Es necesario aproximarse por grados según Newman. Estos grados o formas parciales de alcanzar la verdad son las distintas ciencias. De esta manera, el conjunto de las ciencias se aproxima a ser una representación subjetiva de la verdad objetiva. Sólo cuando el intelecto ha sido debidamente entrenado y formado para lograr una visión coherente de las cosas, se puede desplegar todos sus poderes para conocer la realidad, y sólo así será alcanzable la verdad. La Universidad es el lugar donde las diferentes ciencias se relacionan unas con otras. Así mismo, es donde se aprecia su jerarquía, se cuidan sus campos de acción, se defienden sus métodos y se apuntan sus límites. La armonía entre ciencias tiene como árbitro y juez a la verdad como apunta Newman. Respecto a la jerarquía, esta ordenación de ciencias no sería efectiva si en esta estructura legítima de orden, la Teología no tuviera un lugar preferente. Para Newman, como señala García, Morales y Llano, no hay verdadera universidad sin Teología, debiendo abarcar esta tanto el ámbito filosófico como el religioso. Newman entiende la Universidad como una comunidad viva de intercambio de las ciencias, entre docentes o entre tutores y estudiantes. La Universidad es un lugar de circulación y comunicación del pensamiento cuyo vehículo son las relaciones interpersonales" ${ }^{\text {"16. }}$.

15 Cfr. John Henry Newman, La idea de la Universidad. II. Temas universitarios tratados en Lecciones y Ensayos ocasionales, trad. Victor García Ruiz (Madrid: Encuentro, 2014), 231.

16 Miguel Ángel Martín Sánchez y Jorge Cáceres Muñoz, "La idea de universidad del cardenal John Henry Newman", Cauriensia X (2015): 356. 
Lo que hay detrás es, en el fondo, un replanteamiento radical del modelo de universidad. Esto es justo lo que hace a Newman tan actual y a Ratzinger tomar el testigo de lo iniciado por Newman como refrenda Rumayor:

"Para Newman (1) en la medida en que el conocimiento se estrecha y se hace particular deja de ser sabiduría para la persona y para la sociedad.

Todo lo dicho nos lleva a replantearnos la validez del modelo actual de universidad, al menos aquel que propone el Plan Bolonia, que trata de ser una copia del modelo americano sin iguales recursos físicos y humanos (2). A la sombra de tal modelo, repleto de prácticas y actividades en clase, los alumnos no son formados para expandir sus mentes ni pensar por sí mismos, sino solamente entrenados para desarrollar técnicas medibles, por tanto, en el sentido de Newman, poco formativas (3). Para el intelectual inglés todo conocimiento que no produce acciones inmanentes, cambios profundos en la persona, no forma realmente. Solamente por el crecimiento de estas, la persona va más allá de los objetos conocidos y el ser humano podrá tener después una auténtica proyección vital, una vida creciente capaz de abandonar el límite mental y proyectarse irrestrictamente ante cualquier realidad, tal y como fundamenta Leonardo Polo (1998) desde una reflexión epistemológica" ${ }^{" 17}$.

En este mismo sentido el Papa alemán no coloca el progreso científico-técnico, o la libertad crítica de la razón, en contraposición con la religión y los valores. Reiteradamente manifiesta la grandeza de la inteligencia del hombre capaz de tanto progreso en los avances de la ciencia, la tecnología o los nuevos medios de comunicación. Su denuncia es la reducción de la razón y del hombre al pragmatismo, al positivismo, al relativismo y al subjetivismo y, por tanto, a la pérdida de riqueza de la apertura e inquietud que anidan en el corazón del hombre y apuntan al horizonte trascendente de Dios.

"Una cultura meramente positivista que circunscribiera al campo subjetivo como no científica la pregunta sobre Dios, sería la capitulación de la razón, la renuncia a sus posibilidades más elevadas y consiguientemente una ruina del humanismo, cuyas consecuencias no podrían ser más graves. Lo que es la base

17 Miguel Rumayor, "John Henry Newman y su idea de universidad en el siglo XXI", Educación XX1 22(1) (2019): 318, doi:10.5944/educXX1.20088. Citas dentro del texto: (1) John Henry Newman, The idea of a university (London: Longmans, Green, and Co., 1907), https://goo.gl/Jjg2BJ. (2) Jaime Nubiola, "La transformación de la universidad española", Nueva revista de política, cultura y arte 120 (diciembre de 2008): 81-89. (3) David Luque Mengíbar, "La influencia de John Henry Newman en la reflexión educativa del último medio siglo" (Universidad Complutense Madrid, 2016), https://eprints.ucm .es/40547/. 
de la cultura de Europa, la búsqueda de Dios y la disponibilidad para escucharle, sigue siendo aún hoy el fundamento de toda verdadera cultura"18.

No se entiende cómo es posible dejar afuera de la Universidad la cuestión de Dios desde la razón. La cuestión del sentido reclama esta búsqueda. Omitirla es menospreciar, por un lado, la capacidad de la razón, y, por otro, las inquietudes existenciales del hombre. Si realmente queremos acercarnos a conocer al hombre y su realidad, no podemos despojarlo de su apertura a la trascendencia. Cuando Newman publica en 1870 su Grammar of Assent, persigue esta misma convicción: la razonabilidad de la creencia religiosa es mucho más que un juego de razonabilidad del intelecto puesto que implica la vida entera ${ }^{19}$.

La ciencia acota los procesos en su finitud ${ }^{20}$; la filosofía y la teología los abren al horizonte de sentido. Dejar fuera de la Universidad las preguntas cruciales que dan sentido al mundo y a la vida, y, en especial, si se trata de la cuestión de Dios, es limitar y hacer infértil la vocación universitaria ${ }^{21}$.

"Para Newman, como señala García, Morales y Llano, no hay verdadera universidad sin Teología, debiendo abarcar esta tanto el ámbito filosófico como el religioso. Newman entiende la Universidad como una comunidad viva de intercambio de las ciencias, entre docentes o entre tutores y estudiantes" 22 .

Por otra parte, cómo dejar extramuros aquellas cuestiones que siguen catalizando una gran porción de las discusiones filosóficas de occidente y que están detrás de los grandes problemas irresueltos, como la pobreza o la violencia de los fundamentalismos ${ }^{23}$. El mundo de hoy se mueve más por impresiones o

18 Benedicto XVI, Discurso en el encuentro con el mundo de la cultura en el Collège des Bernardins. París, 12/09/2008.

19 John Henry Newman, Ensayo para contribuir a una gramática del asentimiento., trad. Josep Vives (Madrid: Ediciones Encuentro, S.A., 2010), 164, http://site.ebrary.com/id/10680258.

20 Torralba expresaba: "La ciencia no crea la verdad, sino que la recibe sin poderla justificar, ya que ella no puede fundar sus propios fundamentos” Francesc Torralba Roselló, ¿Por qué creer? La razonabilidad de la fe (Barcelona: Edebé, 2000), 247.

21 Cfr. Benedicto XVI, Discurso a los dirigentes, profesores y alumnos de la Universidad Católica del Sagrado Corazón, 21/05/2011.

22 Miguel A. Martín Sánchez y Jorge Cáceres muñoz, "La idea de universidad del cardenal John Henry Newman", Cauriensia X (2015): 356, doi:http://dx.medra.org/10.17398/1886-4945.10.335. Hace referencia a: Victor García Ruiz, José Morales, y Alejandro Llano, J. H. Newman, hoy (Pamplona: Instituto de Antropología y Ética - Universidad de Navarra, 2011).

23 Valga este botón de muestra: El 7 de enero de 2015, fue el atentado yihadista al semanario satírico Charlie Hebdo; apenas dos días después se había agotado la edición de Voltaire y su "Tratado sobre la tolerancia". Sin ponerse de acuerdo, los franceses necesitaban recuperar las fuentes perdidas de la República. Los editoriales de diarios y contertulios no contuvieron la necesidad de volver a un texto del s. XVIII. Brota la urgencia de recuperar la reflexión sobre el trasfondo de lo que nos acontece. En agosto de 2015, Phillippe-Josheo Salazar, presentaba su libro Palabras armadas. Entre bambalinas, repetía el 
relatos breves que por grandes metarelatos. Sin embargo, cuando el corazón del hombre atraviesa una de sus fronteras vitales, estas explicaciones dadas se nos descubren superficiales y en el mejor de los casos adormecedoras ante la realidad del sufrimiento, el sinsentido o la muerte.

Es un despropósito y una falta a la encomienda depositada por la sociedad despojar a la Universidad de lo relevante y quedarnos solo en los útiles y admirables avances de las ciencias y la técnica. Cómo si unos y otros no se necesitasen, más aún, como si aquellos, los "útiles", fuesen suficientes para sanar las verdaderas preocupaciones del hombre.

La fragmentación y compartimentalización del saber tocan de lleno a la Universidad. La necesaria especialización debe abrirse al entendimiento del todo, y, por ende, a descubrir los propios límites y la belleza del todo, de la verdad que se desvela desde la síntesis de saberes. Repensar nuestro saber desde su designio primero es encontrar las claves donde superar la fragmentación. Se trata de una búsqueda que no se agota pues el misterio permanece ${ }^{24}$, pero a la par, en la tarea de buscador del Absoluto, en los pasos pequeños e inciertos, percibimos y alcanzamos la certeza de que lo finito no puede colmar el anhelo del corazón ${ }^{25}$. Pues bien, esta apertura y replanteamiento del saber exigen el diálogo fecundo de la filosofía y la teología con las ciencias.

No se puede negar la capacidad de la razón para acceder a la Verdad. Capacidad que percibimos escrutando la propia naturaleza, desde la reflexión de la historia

estribillo: los valores que Occidente no ha sabido dar. Philippe-Joseph Salazar, Paroles armées: comprendre et combattre la propagande terroriste (Paris: Lemieux, 2015); María D. Valderrama, "«Los yihadistas del Estado Islámico no están locos ni son imbéciles». Entrevista a Phillippe-Josheo Salazar”, El Mundo, 9 de diciembre de 2015, http://www.elmundo.es/internacional/2015/12/09/566712ece2704eb 21f8b457a.html.

24 Cfr. Benedicto XVI, Audiencia. El Año de la fe. El deseo de Dios, 07/11/2012. En su catequesis sobre S. Anselmo, dos años después, describiendo el alma mística del santo y su continuo camino de búsqueda, recordará: "S. Anselmo cultivó un intenso deseo de profundizar en los misterios divinos, pero plenamente consciente de que el camino de búsqueda de Dios nunca se termina, al menos en esta tierra. La claridad y el rigor lógico de su pensamiento tuvieron siempre como objetivo "elevar la mente a la contemplación de Dios". La actividad del teólogo, según san Anselmo, se desarrolla así en tres fases: la fe, don gratuito de Dios que hay que acoger con humildad; la experiencia, que consiste en encarnar la Palabra de Dios en la propia existencia cotidiana; y por último el verdadero conocimiento, que nunca es fruto de razonamientos asépticos, sino de una intuición contemplativa. Al respecto, para una sana investigación teológica y para quien quiera profundizar en las verdades de la fe, siguen siendo muy útiles también hoy sus célebres palabras: "No pretendo, Señor, penetrar en tu profundidad, porque no puedo ni siquiera de lejos confrontar con ella mi intelecto; pero deseo entender, al menos hasta cierto punto, tu verdad, que mi corazón cree y ama. No busco entender para creer, sino que creo para entender"“ Benedicto XVI, Audiencia. El Año de la fe. El deseo de Dios, 07/11/2012; Audiencia general. San Anselmo, 23/9/2009. Las referencias las toma de S. ANSELMO, Proemium, 1. (Cit. en el mismo texto).

25 Cfr. Benedicto XVI, Audiencia. El Año de la fe. El deseo de Dios, 07/11/2012. 
o del propio acontecer. Dicha capacidad choca y anula frontalmente el escepticismo y el relativismo, y posibilita el diálogo con los no creyentes y la pretensión de que las afirmaciones procedentes de la fe valgan para quienes no la comparten.

Ensanchar los horizontes de la racionalidad es lo más nuclear de la visión de Newman y Ratzinger y la clave de bóveda de su idea de Universidad. Se trata de ampliar la razón en diálogo con la fe, frente a las patologías del fideísmo que menosprecia la razón, o del racionalismo, que hace lo mismo con la fe. La Universidad es el encuentro discursivo entre personas que buscan cooperativamente la verdad y que cultivan su humanidad en toda su amplitud: artes ad humanitatem. Este ethos discursivo propio de la Universidad requiere poner en el centro a la verdad y a la persona, lo cual estructura una atmósfera de confianza, cordialidad, diálogo y tolerancia.

En 2015 celebrábamos el $50^{\circ}$ aniversario de la Declaración Gravissimun educationis y el $25^{\circ}$ de la Constitución Apostólica Ex Corde Ecclessiae. Fue Benedicto XVI quien, consciente de la centralidad de la educación, en 2011, convocó a los miembros de la Asamblea Plenaria de la Congregación para la Educación Católica con la encomienda de preparar tales aniversarios. El fruto de esas reflexiones, lo presentaba el 7 de abril de 2014 el cardenal Zenon Grocholewski, Prefecto de la Congregación para la Educación Católica y Gran Canciller de la Pontificia Universidad Gregoriana, con el Instrumentum Laboris "Educar hoy y mañana. Una pasión que se renueva". Extraigo un párrafo que resume la cuestión del sentido:

"La escuela y la universidad son lugares que introducen a los saberes y a la dimensión de la investigación científica. Una de las principales responsabilidades de los enseñantes es acercar las jóvenes generaciones al conocimiento y a la comprensión de las conquistas del conocimiento y sus aplicaciones. Pero el compromiso por conocer e investigar no va separado del sentido ético y de lo transcendente. No hay verdadera ciencia que pueda descuidar sus consecuencias éticas y no hay verdadera ciencia que aleje de la transcendencia. Ciencia y eticidad, ciencia y transcendencia no se excluyen recíprocamente, pero se conjugan para una mayor y mejor comprensión del hombre y de la realidad del mundo" 26 .

Un último apunte: el mundo, nuestra existencia, nuestra realidad, nuestro pensar sobre el sentido reclaman una respuesta desde la razón y la fe. No basta la interpretación del cientifismo o del existencialismo ateo y su percepción de

26 Congregación para la Educación Católica, Educar hoy y mañana. Una pasión que se renueva. Instrumentum laboris (Ciudad del Vaticano, 2014), 2. 
la existencia como algo absurdo o inútil, fruto del azaroso devenir de agentes químicos para explicar el profundo anhelo del hombre. No se trata de demostrar a Dios sino de descubrir la razonabilidad de escrutar sus caminos.

Ratzinger, en su obra Caminos de Jesucristo, al delinear el problema de la existencia de Dios y la confrontación con el principio de objetividad de Monod $^{27}$, afirma:

"En definitiva [la decisión a favor de Dios] es una decisión a favor de la razón, y una decisión respecto a si el bien y el mal, la verdad o la falsedad son simplemente categorías subjetivas o son realidad. En este sentido, al principio está la fe, la única que ofrece su dignidad y amplitud a la razón. (...) La decisión a favor de Dios es una decisión del pensamiento [intelectual] y al mismo tiempo de la vida [existencial], es decir, ambos se condicionan recíprocamente"28.

Es propio del cristianismo su alianza con la filosofía y la razonabilidad de la $\mathrm{fe}^{29}$. La fe y la razón caminan juntas en el origen de la Universidad, y aunque esos caminos se hayan separado, la originaria asociación de ambas contribuyó a que el discurso universitario fuese una racionalidad abierta, no mutilada o transida del corto alcance de la razón instrumental o del pragmatismo. Servir al hombre en su totalidad exige recuperar la vocación primera de la Universidad.

27 Así lo plantea: "La negativa sistemática de considerar capaz de conducir a un conocimiento "verdadero" toda interpretación de los fenómenos dada en términos de causas finales, es decir, de "proyectos" [...] Postulado puro, por siempre indemostrable, porque evidentemente es imposible imaginar una experiencia que pudiera probar la no existencia de un proyecto, de un fin perseguido, en cualquier parte de la naturaleza Mas el postulado de objetividad es consustancial a la ciencia, ha guiado todo su prodigioso desarrollo desde hace tres siglos. Es imposible desembarazarse de él, aunque solo sea provisionalmente, o en un ámbito limitado, sin salir de la misma ciencia” Jacques Monod, El azar y la necesidad. Ensayo sobre la filosofia natural de la biología moderna (Barcelona: Barral Editores, 1970), 31. Tal postulado deriva en condición necesaria negando cualquier posibilidad de deber ser: "Desde el momento en que se propone el postulado de la objetividad como condición necesaria de toda verdad en el conocimiento, una distinción radical, indispensable en la búsqueda de la verdad, es establecida entre el dominio de la ética y el del conocimiento. E1 conocimiento en sí mismo es excluyente de todo juicio de valor, mientras que la ética, por esencia no objetiva, está siempre excluida del campo del conocimiento" Ibid. 177-178. "La antigua alianza esta ya rota; el hombre sabe al fin que está solo en la inmensidad indiferente del Universo de donde ha emergido por azar. Igual que su destino, su deber no está escrito en ninguna parte" Ibid. 193.

28 Joseph Ratzinger, Caminos de Jesucristo, 2.a ed. (Madrid: Ediciones Cristiandad, 2005), 65. Sobre ello, Pablo Blanco afirmará: "La fe se dirige al afecto, a la voluntad y a la inteligencia. Por eso no supone en ningún momento el olvido de la razón, la renuncia a la propia actividad intelectual. Quien separa demasiado el Dios de la fe del Dios de los filósofos, arrebata su objetividad a la fe y separa de nuevo al objeto del sujeto en dos universos distintos" Pablo Blanco Sarto, La teología de Joseph Ratzinger: una introducción (Madrid: Ediciones Palabra, 2011), 147.

29 Cfr. Joseph Ratzinger, "Vérité du christianisme? Colloque 2000 ans après quoi? Sorbonne, 2527 novembre 2000”, La Documentation catholique n. 2217 (2 de enero de 2000): 31 ss. 
"El nacimiento de las universidades europeas fue fomentado por la convicción de que la fe y la razón están destinadas a cooperar en la búsqueda de la verdad, respetando cada una la naturaleza y la legítima autonomía de la otra, pero trabajando juntas de forma armoniosa y creativa al servicio de la realización de la persona humana en la verdad y en el amor"30.

\section{LA CONCIENCIA COMO SANTUARIO DE LA PERSONA Y SU LIBERTAD}

La idea de Newman de la conciencia como santuario de la persona y de su libertad $^{31}$ estuvo presente en Ratzinger desde que comenzó a estudiar en el seminario de Frisinga de la mano de Theodor Steinbüchel, su profesor de moral. Newman tuvo la "firme voluntad de adherirse al maestro interior con la propia conciencia, de abandonarse confiadamente al Padre y de vivir en la fidelidad a la verdad reconocida" 32 . Esta primacía de la conciencia no es una cuestión de certidumbre subjetiva sino "la presencia perceptible e imperiosa de la voz de la verdad dentro del sujeto mismo" 33 .

"Cuando un relativismo intelectual y moral amenaza con minar la base misma de nuestra sociedad, Newman nos recuerda que, como hombres y mujeres a imagen y semejanza de Dios, fuimos creados para conocer la verdad, y encontrar en esta verdad nuestra libertad última y el cumplimiento de nuestras aspiraciones humanas más profundas" ${ }^{34}$.

Por otra parte, la vivencia de la presión del régimen nazi en Alemania durante los años de la guerra reforzó la idea de conciencia de Ratzinger tomada de Newman. Él mismo escribe, precisamente en el discurso del Centenario de la muerte de John Henry Newman:

"Habíamos experimentado la pretensión de un partido totalitario que se consideraba la plenitud de la historia y que negaba la conciencia del individuo. Hermann Goering había dicho de su jefe: "¡Yo no tengo ninguna conciencia! Mi

30 Benedicto XVI, Discurso a los participantes en el Encuentro europeo de profesores universitarios, 23/06/2007.

31 Pablo Blanco Sarto, Joseph Ratzinger--Benedicto XVI: un mapa de sus ideas, Estudios y ensayos. Teología (Madrid: Biblioteca de Autores Cristianos, 2012), 9.

32 Benedicto XVI, Mensaje con ocasión del Simposio organizado por el Centro Internacional Amigos de Newman, 18/11/2010.

33 Joseph Ratzinger, Ser cristiano en la era neopagana, ed. José Luis Restán (Madrid: Ediciones Encuentro, 1995), 29.

34 Benedicto XVI, Saludo en la Vigilia de oración por la beatificación del cardenal John Henry Newman en Hyde Park. Londres, 18/09/2010. 
conciencia es Adolf Hitler". La inmensa ruina del hombre que derivó de esto, estaba ante nuestros ojos"

Y continúa diciendo:

"Por eso, para nosotros era un hecho liberador y esencial saber que el "nosotros" de la Iglesia no se basaba en la eliminación de la conciencia, sino que sólo podía desarrollarse a partir de la conciencia. Precisamente porque Newman explicaba la existencia del hombre a partir de la conciencia, es decir, en la relación entre Dios y el alma"36.

Cabe notar que la conciencia no llama al individualismo sino todo lo contrario. Como espacio sagrado de la libertad demanda por un lado a la comunidad (al "nosotros" de la Iglesia, al "nosotros" de la universidad) y está en armonía con la sabiduría que viene de la Revelación y que completa lo que el hombre apenas vislumbra de manera incompleta.

Buscar el sentido, es, por un lado, indagar en la cuestión última y en la razón de ser, ahondar en la vida e historia personal para encontrarse con el propio drama de la existencia y abrirse a una luz de comprensión mayor que nos asom$\mathrm{bra}^{37}$. Dicha luz no es un sentimiento sino un encuentro desde la razonabilidad de la fe que supera la certeza de la subjetividad. Por otro, es una labor del "nosotros", del "ayuntamiento" de profesores y estudiantes ${ }^{38}$. A la inversa, cuando solo se busca en las propias convicciones uno muere en esas mismas convicciones, sin avanzar más. Es la historia mil veces repetida del absurdo y la apatía del sinsentido, de Mersault ${ }^{39}$ incapaz de llorar ante su madre muerta.

\section{VERDAD Y VIDA}

Fruto de esa idea de conciencia es el testimonio vital de la verdad. "Las grandes figuras, como Tomás Moro, el cardenal Newman y otros, que supieron

35 Benedicto XVI, Discorso di Sua Eminenza il Card. Joseph Ratzinger in occasione del centenario della morte del Card. John Henry Newman, 28/04/1990.

36 Ibid.

37 Asombro tomado desde su significado etimológico, ad - umbra, hacia la sombra que nos provoca una luz mayor, que nos hace conscientes de nuestra pequeñez y nos anima salir de ella.

38 En referencia al texto de Alfonso X el Sabio (c. 1256): "Estudio es ayuntamiento de maestros y escolares, que es hecho en algún lugar con voluntad y con entendimiento de aprender los saberes", Siete Partidas, Tít. 31

39 En referencia al personaje de El Extranjero de A. Camus (1942) 
dar testimonio de la verdad -como muchos de los perseguidos por el régimen nazi, como Dietrich Bonhoeffer-, son mis mejores modelos" ${ }^{40}$.

"Newman, como hombre de la conciencia, se transforma en un converso; fue su conciencia que lo condujo desde los antiguos vínculos y las antiguas certezas dentro del mundo para él difícil e inusual del catolicismo. Pero precisamente esta vía de la conciencia es algo distinto a una vía de la subjetividad que se afirma a sí misma: es, en cambio, una vía de la obediencia a la verdad objetiva"${ }^{41}$.

Respecto a nuestra pregunta por el sentido último esto nos da una poderosa luz: alcanzar la verdad siempre va ligado a la existencia vital. Nuevamente el binomio creer y comprender (que es mucho más que entender, porque a veces comprendemos sin necesidad de conocer su detalle o mecanismo).

Benedicto hará suya la convicción profunda de la interdependencia del saber de Newman (circle of knowledge) y su necesaria unidad donde solo Dios tiene relación con la totalidad de lo real ${ }^{42}$.

Estamos comprometidos con la búsqueda de la verdad, del bien y la belleza intentando descifrar aquellas claves que den sentido a nuestro existir, a nuestro enseñar, al por qué de la vida y la muerte, del tiempo y la historia. No es algo que llegue a acabarse. La historia de la salvación en la que estamos inmersos no es estática sino dinámica. Ratzinger en el discurso con ocasión del centenario de la muerte del cardenal Newman, expresa:

"En el concepto de desarrollo está en juego la misma vida personal de Newman. Pienso que esto se hace evidente en su conocida afirmación, contenida en el famoso ensayo sobre "El desarrollo de la doctrina cristiana": "aquí sobre la tierra vivir es cambiar, y la perfección es el resultado de muchas transformaciones". Newman ha sido, a lo largo de toda su vida, alguien que se ha convertido, alguien que se ha transformado, y de este modo ha seguido siendo siempre él mismo y ha llegado a ser cada vez más él mismo"43.

Ratzinger cierra el discurso señalando uno de los signos característicos de Newman: no enseñaba "sólo con su pensamiento y sus discursos sino también

40 Joseph Ratzinger y Peter Seewald, La sal de la tierra: cristianismo e Iglesia Católica ante el nuevo milenio : una conversación con Peter Seewald, trad. Carla Arregui Núñez, 6.a ed. (Madrid: Ediciones Palabra, 2005), 40.

41 Ratzinger, Discorso del Card. Ratzinger nel centenario della morte del Card. John H. Newman.

42 Cfr. Benedicto XVI, Discurso a los participantes en la Plenaria de la Congregación para la Educación Católica, 07/02/2011.

43 Ratzinger, Discorso del Card. Ratzinger nel centenario della morte del Card. John H. Newman. 
con su vida, ya que en él pensamiento y vida se compenetran y se determinan recíprocamente" 44 . He aquí una piedra angular para el acercamiento a la pregunta sobre el sentido último: un conocimiento que se hace vida, una vida que se hace conocimiento; razón y fe, comprender y creer.

\section{HABLAR AL CORAZÓN}

Víctor García afirma que Newman atrae porque habla "con singular agudeza al entendimiento, pero sobre todo porque habla al corazón" 45 . No en vano su lema cardenalicio: "cor ad cor loquitur" 46 . Benedicto XVI sobre él afirmará que no solo desvela el modo del camino, desde el corazón, sino su origen y fin último, esto es, "entrar en comunión íntima con el Corazón de Dios" $"$.

Esta idea de "hablar al corazón" desde la comunión con Aquel que ya nos ha alcanzado antes que nosotros iniciemos el camino, transitará todo el pensamiento de Juan Pablo II, en especial en su reflexión sobre el nacimiento de la universidad ("Ex corde Ecclesiae", esto es, nacida del corazón de la Iglesia) ${ }^{48}$. Solo desde ese origen se entiende el gozo de buscar la verdad -el gaudium de veritate $^{49}$-, descubrirla y comunicarla en todos los campos del conocimiento ${ }^{50}$. Es lo propio de la Universidad y en esta realidad primera está en juego su existencia misma. Esta libre reunión de maestros y escolares animados "por el mismo amor al saber" tiene una vocación específica: consagrarse a la investigación, la enseñanza y la formación" ${ }^{51}$. Su tarea es "unificar existencialmente en el trabajo intelectual dos órdenes de realidades que muy a menudo se tienden a

44 Ibid., Ratzinger.

45 García Ruíz, “«Cor ad cor loquitur». El poderoso lenguaje de John Henry Newman”, 444.

46 TdA. "El corazón habla al corazón".

47 Benedicto XVI, Homilía durante la Santa Misa de beatificación del venerable cardenal John Henry Newman en el Cofton Park de Rednal, Birmingham (Reino Unido), 19/9/2010.

48 Juan Pablo II, Constitución Apostólica "Ex Corde Ecclesiae" (Roma: AAS 82 (1990) 14751509 - Libreria Editrice Vaticana, 15.08.1990), 1, accedido 16 de junio de 2015, https://tinyurl.com/ y4tdbbqz

49 La expresión está tomada de S. Agustín: "todos quieren el gozo de la verdad (gaudium de veritate)". Agustín de Hipona, Obras de san Agustín. II, Las confesiones. Texto bilingüe, ed. Ángel Custodio Vega, 5.a ed. (Madrid: Editorial Católica, 1968), X, XXIII, 33, https://tinyurl.com/y2xprl4y. Si bien en san Agustín tal gozo es "de ti, que eres la verdad, joh Dios, luz mía, salud de mi rostro, Dios mío! [en ref. al texto de Gal 5,7]" Gozo que es posible a todos en cuanto "Todos desean esta vida feliz; todos quieren esta vida, la sola feliz; todos quieren el gozo de la verdad (gaudium de veritate) '. Ibid. Capítulo que dará paso para entender el siguiente de "Dios en la memoria" Ibid. X, XXIV, 35.

50 Cfr. Juan Pablo II, Constitución Apostólica "Ex Corde Ecclesiae", 1.

51 Cfr. Alfredo H. Zecca, "«Ex corde ecclesiae»: una lectura a 20 años de su promulgación”, Humanitas - Pontificia Universidad Católica de Chile - Revista de Antropología y Cultura Cristiana, accedido 6 de noviembre de 2015, https://tinyurl.com/y3q8dhhs. 
oponer como si fuesen antitéticas: la búsqueda de la verdad y la certeza de conocer ya la fuente de la verdad",52.

Benedicto XVI hará suyo este gozo de buscar la verdad tan agustiniano recuperando la esencia de la Universidad desde la razón apasionada capaz de acceder a la Verdad. Gozo de buscar la verdad que es tarea fascinante ${ }^{53}$, y a la par, comprometedora, pues debe "interpretar las dinámicas sociales y culturales, ofreciendo soluciones no abstractas, sino concretas y realistas" $" 54$.

He aquí una clave para entender la cuestión del sentido: la Universidad no es un ente aislado o un repositorio de conocimientos más allá de su entorno y su acontecer histórico. Surge precisamente porque aquellas primeras escuelas monacales, catedralicias, parroquiales, palatinas o municipales ${ }^{55}$ abrieron su búsqueda y saber a la sociedad, pero, sobre todo, porque había un empeño de encontrar la Verdad última, la fuente de sentido, capaz de dar respuesta a los desafíos que latían de fondo.

\section{UNA ESPECIAL PEDAGOGÍA}

Una última nota sobre su especial pedagogía en la defensa de la verdad. Así lo cuenta Benedicto XVI: "Newman siempre estuvo atento también a encontrar el lenguaje apropiado, la forma justa y el tono adecuado. Trató de no ofender nunca y de dar testimonio de la amable luz interior ("kindly light"), esforzándose por convencer con humildad, alegría y paciencia" 56 .

52 Juan Pablo II, Constitución Apostólica "Ex Corde Ecclesiae", 1. Citando a su vez un texto suyo: Discurso al Instituto de París, 1-VI-1980: Insegnamenti di Giovanni Paolo II, vol. III/1 (1980), p. 1581.

53 En diversas ocasiones Benedicto XVI calificará el gozo de buscar la verdad como tarea fascinante: Benedicto XVI, Discurso a los participantes en la IV Asamblea nacional de la Iglesia en Italia, 19/10/2006; Discurso a los participantes en el primer Encuentro Europeo de Estudiantes Universitarios, organizado por la Comisión de catequesis, escuelas y universidades del Consejo de las Conferencias Episcopales Europeas (CCEE), 11/07/2009; Discurso a los participantes en la Asamblea plenaria del Consejo pontificio para la Cultura, 13/11/2010; Homilía en la celebración de las Visperas con los universitarios romanos en la preparación de Navidad, 16/12/2010; Mensaje para la Celebración de la XLV Jornada Mundial de la Paz, 08/12/2011, etc.

54 Benedicto XVI, Homilía en la celebración de las Vísperas con los universitarios romanos en la preparación de Navidad, 16/12/2010.

55 Incluimos estas dos últimas pues igualmente estaban impregnadas del espíritu cristiano y en el fondo de un anhelo de saber último.

56 Benedicto XVI, Mensaje con ocasión del Simposio organizado por el Centro Internacional Amigos de Newman, 18/11/2010. 
Benedicto XVI no habla de provocar sino de "suscitar" 57 . No se trata de dar respuestas sino de suscitar su búsqueda y descubrimiento creíble ${ }^{58}$. Por ello, urge educar desde "la valentía de tomar decisiones definitivas, que en realidad son las únicas que permiten crecer, caminar hacia adelante y lograr algo importante en la vida; son las únicas que no destruyen la libertad, sino que le indican la justa dirección en el espacio. Tener el valor de dar este salto a algo definitivo, acogiendo así plenamente la vida" ${ }^{\circ 9}$.

El Papa marcaba las claves de esta nueva pedagogía en la catequesis sobre "el deseo de Dios" en el Año de la fe:

"Sería de gran utilidad, a tal fin, promover una especie de pedagogía del deseo, tanto para el camino de quien aún no cree como para quien ya ha recibido el don de la fe. Una pedagogía que comprende al menos dos aspectos.

En primer lugar, aprender o re-aprender el gusto de las alegrías auténticas de la vida.

[...] Un segundo aspecto, que lleva el mismo paso del precedente, es no conformarse nunca con lo que se ha alcanzado. Precisamente las alegrías más verdaderas son capaces de liberar en nosotros la sana inquietud que lleva a ser más exigentes - querer un bien más alto, más profundo - y a percibir cada vez con mayor claridad que nada finito puede colmar nuestro corazón. Aprenderemos así a tender, desarmados, hacia ese bien que no podemos construir o procurarnos con nuestras fuerzas, a no dejarnos desalentar por la fatiga o los obstáculos que vienen de nuestro pecado"60.

Se trata de "suscitar esa sed de verdad que poseen [los jóvenes] en lo profundo, y ese afán de superación" $"$. Hay que partir de su situación concreta y

57 Cfr. Benedicto XVI, Homilía en la santa Misa en la explanada de Isling de Ratisbona, 12/09/2006; Discurso a los participantes en la IV Asamblea nacional de la Iglesia en Italia., 19/10/2006; Discurso en la inauguración de los trabajos de la Asamblea Diocesana de Roma., 11/06/2007; Discurso preparado para el encuentro con la Universidad La Sapienza de Roma (Visita cancelada el 15 de enero de 2008); etc.

58 "Testigos elocuentes y creíbles" Benedicto XVI, Discurso a los participantes en la Plenaria de la Pontificia Comisión para América Latina., 20/01/2007.

59 Benedicto XVI, Entrevista de Radio Vaticano y cuatro cadenas alemanas (Bayerischer Rundfunk-BR, ARD, ZDF y Deutsche Welle-DW) con motivo de su próximo viaje apostólico a Alemania, 05/08/2006.

60 Benedicto XVI, Audiencia. El Año de la fe. El deseo de Dios, 07/11/2012.

61 Benedicto XVI, Discurso en el encuentro con los jóvenes profesores universitarios en la Basílica de San Lorenzo de El Escorial, 19/08/2011. 
descubrir la verdad ontológico-metafísica que en ella se esconde ${ }^{62}$, invitar a salir de uno mismo para ir al encuentro con la Verdad. Se trata, en fin, de "suscitar perenne asombro" ${ }^{63}$ ante ella.

En 1832 Newman inicia un viaje a Italia que será una experiencia fundante. El descubrimiento de Roma le fascinará y a la par le atormentará. Necesita entender. En el viaje de retorno de Sicilia (1833) escribe The Pillar of Cloud, un poemario-oración cuyo estribillo es nuevamente la entrega decidida a seguir la verdad:

"Lead, Kindly Light, amid the encircling gloom,

Lead Thou me on!

The night is dark, and I am far from home,

Lead Thou me on!

Keep Thou my feet; I do not ask to see

The distant scene- one step enough for me". ${ }^{4}$

Dawson relata que regresó a Inglaterra "como un hombre renacido, con todas sus facultades en acción y con una energía y una confianza tan exuberantes que sus amigos de Oxford apenas lo reconocían. Había dejado atrás todas sus dudas y vacilaciones" ${ }^{\prime 65}$. Hacerse la pregunta sobre el sentido en la universidad es embarcarse en el latir de la verdad, el ser y el actuar en cada ciencia para desentrañar el verdadero sentido del quehacer universitario donde se pone en juego la vida misma de profesores y alumnos ${ }^{66}$. Tarea que no es sencilla pero sí imprescindible. Así nos invitaba Benedicto XVI en el encuentro con los jóvenes universitarios en la Basílica de San Lorenzo de El Escorial (Madrid):

"Por tanto, os animo encarecidamente a no perder nunca dicha sensibilidad e ilusión por la verdad; a no olvidar que la enseñanza no es una escueta comunicación de contenidos, sino una formación de jóvenes a quienes habéis de

62 Cfr. Benedicto XVI, Discurso a los participantes en el VI Simposio Europeo de Profesores Universitarios, 07/06/2008.

63 Benedicto XVI, Discurso durante la visita a la Pontificia Universidad Lateranense con motivo de la inauguración del año académico, 21/10/2006. El cardenal Poupard comentará la necesidad de gestar una verdadera païdeia que valore la inteligencia para equilibrar el sentimiento, lo cual tiene "un potencial irreprochable de asombro" (TdA: "un potentiel inentamé d'emerveillement") Paul Poupard, Le christianisme à l'aube du IIIe millénaire (Paris: Plon : Mame, 1999), 136.

64 "Guíame, Luz Buena, entre tanta niebla espesa, / ¡Llévame Tú! / Estoy lejos de casa, es noche prieta y densa, / ¡Llévame Tú! / Guarda mis pasos; no pido ver / confines ni horizontes, solo un paso más me basta".16 de junio de 1833. Traducción de Víctor García Ruiz

65 Dawson, El espíritu del movimiento de Oxford, 76.

66 Cfr. María Lacalle Noriega, En busca de la unidad del saber: una propuesta para renovar las disciplinas universitarias (Madrid: Universidad Francisco de Vitoria, 2014), 41. 
comprender y querer, en quienes debéis suscitar esa sed de verdad que poseen en lo profundo y ese afán de superación. Sed para ellos estímulo y fortaleza" ${ }^{" 67}$.

\section{REFERENCIAS BIBLIOGRÁFICAS}

Agustín de Hipona. Obras de san Agustín. II, Las confesiones. Texto bilingüe. Editado por Ángel Custodio Vega. 5. ${ }^{a}$ ed. Madrid: Editorial Católica, 1968. https://tinyurl.com/y2xprl4y.

Benedicto XVI, Audiencia. El Año de la fe. El deseo de Dios, 07/11/2012.

Benedicto XVI. Audiencia general. San Anselmo, 23/9/2009.

Benedicto XVI. Carta al Card. Giacomo Biffi, Enviado especial para las celebraciones del IX centenario de la muerte de San Anselmo, 15/04/2009.

Benedicto XVI. Discorso di Sua Eminenza il Card. Joseph RAtzinger in occasione del centenario della morte del Card. John Henry Newman, 28/04/1990.

Benedicto XVI. Discurso a los dirigentes, profesores y alumnos de la Universidad Católica del Sagrado Corazón, 21/05/2011.

Benedicto XVI. Discurso a los participantes en el Encuentro europeo de profesores universitarios, 23/06/2007.

Benedicto XVI. Discurso a los participantes en el primer Encuentro Europeo de Estudiantes Universitarios, organizado por la Comisión de catequesis, escuelas y universidades del Consejo de las Conferencias Episcopales Europeas (CCEE), 11/07/2009;

Benedicto XVI. Discurso a los participantes en el VI Simposio Europeo de Profesores Universitarios, 07/06/2008.

Benedicto XVI. Discurso a los participantes en la Asamblea plenaria del Consejo pontificio para la Cultura, 13/11/2010;

Benedicto XVI. Discurso a los participantes en la IV Asamblea nacional de la Iglesia en Italia, 19/10/2006;

Benedicto XVI. Discurso a los participantes en la Plenaria de la Congregación para la Educación Católica, 07/02/2011.

Benedicto XVI. Discurso a los participantes en la Plenaria de la Pontificia Comisión para América Latina., 20/01/2007.

Benedicto XVI. Discurso durante la Inauguración del $85^{\circ}$ Año Académico de la Universidad Católica del Sagrado Corazón, 25/11/2005.

Benedicto XVI. Discurso durante la visita a la Pontificia Universidad Lateranense con motivo de la inauguración del año académico, 21/10/2006.

Benedicto XVI. Discurso en el encuentro con el mundo de la cultura en el Collège des Bernardins. París, 12/09/2008.

67 Benedicto XVI, Discurso en el encuentro con los jóvenes profesores universitarios en la Basílica de San Lorenzo de El Escorial., 19/08/2011. 
Benedicto XVI. Discurso en el encuentro con el mundo de la cultura en el Patio Teresiano de la Universidad de Pavía, 22/04/2007.

Benedicto XVI. Discurso en el encuentro con los jóvenes profesores universitarios en la Basílica de San Lorenzo de El Escorial., 19/08/2011.

Benedicto XVI. Entrevista de Radio Vaticano y cuatro cadenas alemanas (Bayerischer Rundfunk-BR, ARD, ZDF y Deutsche Welle-DW) con motivo de su próximo viaje apostólico a Alemania, 05/08/2006.

Benedicto XVI. Homilía durante la Santa Misa de beatificación del venerable cardenal John Henry Newman en el Cofton Park de Rednal, Birmingham (Reino Unido), 19/9/2010.

Benedicto XVI. Homilía en la celebración de las Vísperas con los universitarios romanos en la preparación de Navidad, 16/12/2010;

Benedicto XVI. Homilía en la santa Misa en la explanada de Isling de Ratisbona, 12/09/2006; Discurso a los participantes en la IV Asamblea nacional de la Iglesia en Italia., 19/10/2006;

Benedicto XVI. Discurso en la inauguración de los trabajos de la Asamblea Diocesana de Roma., 11/06/2007;

Benedicto XVI. Discurso preparado para el encuentro con la Universidad La Sapienza de Roma (Visita cancelada el 15 de enero de 2008); etc.

Benedicto XVI. Mensaje con ocasión del Simposio organizado por el Centro Internacional Amigos de Newman, 18/11/2010.

Benedicto XVI. Mensaje para la Celebración de la XLV Jornada Mundial de la Paz, 08/12/2011.

Benedicto XVI. Saludo en la Vigilia de oración por la beatificación del cardenal John Henry Newman en Hyde Park. Londres, 18/09/2010

Blanco Sarto, Pablo. Joseph Ratzinger--Benedicto XVI: un mapa de sus ideas. Estudios y ensayos. Teología. Madrid: Biblioteca de Autores Cristianos, 2012.

Blanco Sarto, Pablo. La teología de Joseph Ratzinger: una introducción. Madrid: Ediciones Palabra, 2011.

Congregación para la Educación Católica. Educar hoy y mañana. Una pasión que se renueva. Instrumentum laboris. Ciudad del Vaticano, 2014.

Dawson, Christopher. El espíritu del movimiento de Oxford. Traducido por José Morales. Madrid: Rialp, 2000.

García Ruíz, Víctor. "«Cor ad cor loquitur». El poderoso lenguaje de John Henry Newman". Scripta Theologica - Universidad de Navarra 33 (febrero de 2001): 441-62.

García Ruiz, Victor, José Morales, y Alejandro Llano. J. H. Newman, hoy. Pamplona: Instituto de Antropología y Ética - Universidad de Navarra, 2011.

Juan Pablo II. Constitución Apostólica "Ex Corde Ecclesiae". Roma: AAS 82 (1990) 1475-1509 - Libreria Editrice Vaticana, 15.08.1990. Accedido 16 de junio de 2015. https://tinyurl.com/y4tdbbqz 
Lacalle Noriega, María. En busca de la unidad del saber: una propuesta para renovar las disciplinas universitarias. Madrid: Universidad Francisco de Vitoria, 2014.

Luque Mengíbar, David. "La influencia de John Henry Newman en la reflexión educativa del último medio siglo". Universidad Complutense Madrid, 2016. https://eprints.ucm.es/40547/.

Luque, Mónica Georgina. La idea de universidad: estudios sobre Newman, Ortega y Gasset y Jaspers. Washington: INTERAMER. Serie educativa, 1993.

Martín Sánchez, Miguel A., y Jorge Cáceres muñoz. "La idea de universidad del cardenal John Henry Newman". Cauriensia X (2015): 335-58. doi:http://dx.medra.org/10.17398/1886-4945.10.335.

Martín Sánchez, Miguel Ángel, y Jorge Cáceres Muñoz. "La idea de universidad del cardenal John Henry Newman". Cauriensia X (2015): 335-58.

Monod, Jacques. El azar y la necesidad. Ensayo sobre la filosofia natural de la biología moderna. Barcelona: Barral Editores, 1970.

Newman, John Henry. Apologia pro vita sua: historia de mis ideas religiosas. Traducido por Victor García Ruiz y José Morales. Edición conmemorativa. Madrid: Ediciones Encuentro, S.A., 2019.

Newman, John Henry. Ensayo para contribuir a una gramática del asentimiento. Traducido por Josep Vives. Madrid: Ediciones Encuentro, S.A., 2010. http://site.ebrary.com/id/10680258.

Newman, John Henry. La idea de la Universidad. II. Temas universitarios tratados en Lecciones y Ensayos ocasionales. Traducido por Victor García Ruiz. Madrid: Encuentro, 2014.

Newman, John Henry. Perder y ganar. Traducido por Victor García Ruiz. Madrid: Encuentro, 2017.

Newman, John Henry. The idea of a university. London: Longmans, Green, and Co., 1907. https://goo.gl/Jjg2BJ.

Nubiola, Jaime. "La transformación de la universidad española". Nueva revista de politica, cultura y arte 120 (diciembre de 2008): 81-89.

Poupard, Paul. Le christianisme à l'aube du IIIe millénaire. Paris: Plon : Mame, 1999.

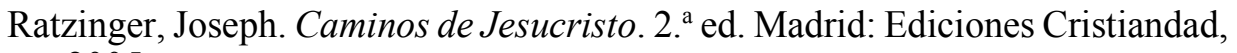
2005.

Ratzinger, Joseph. Discorso del Card. Ratzinger nel centenario della morte del Card. John H. Newman. Roma: Archivio della Congregazione per la Dottrina della Fede (novembre 1981-aprile 2005), 1990. http://www.vatican.va/roman_curia/congregations/cfaith/documents/rc_con_cfaith_doc_19900428_ratzinger-newman_it.html.

Ratzinger, Joseph. Mi vida: recuerdos 1927-1977. Traducido por Carlos d'Ors Führer. 2. ${ }^{a}$ ed. Madrid: Ediciones Encuentro, 2006.

Ratzinger, Joseph. "Presentación a cargo de su eminencia el cardenal Joseph Ratzinger con ocasión del primer centenario de la muerte del cardenal John 
Henry Newman, Roma, 28 de abril de 1990”. En Apologia pro vita sua. Historia de mis ideas religiosas, traducido por Federico de Carlos Otto, 914. Madrid: Ciudadela Libros, 2009. http://www.vatican.va/roman_cu$\mathrm{ria} /$ congregations/cfaith/documents/rc_con_cfaith_doc_19900428_ratzinger-newman_en.html.

Ratzinger, Joseph. Ser cristiano en la era neopagana. Editado por José Luis Restán. Madrid: Ediciones Encuentro, 1995.

Ratzinger, Joseph. "Vérité du christianisme? Colloque 2000 ans après quoi? Sorbonne, 25-27 novembre 2000". La Documentation catholique n. 2217 (2 de enero de 2000): 29-35.

Ratzinger, Joseph, y Peter Seewald. La sal de la tierra: cristianismo e Iglesia Católica ante el nuevo milenio: una conversación con Peter Seewald. Traducido por Carla Arregui Núñez. 6. ${ }^{\mathrm{a}}$ ed. Madrid: Ediciones Palabra, 2005.

Rumayor, Miguel. "John Henry Newman y su idea de universidad en el siglo XXI”. Educación XX1 22(1) (2019): 315-33. doi:10.5944/educXX1.20088.

Salazar, Philippe-Joseph. Paroles armées: comprendre et combattre la propagande terroriste. Paris: Lemieux, 2015.

Torralba Roselló, Francesc. ¿Por qué creer? La razonabilidad de la fe. Barcelona: Edebé, 2000.

Valderrama, María D. "«Los yihadistas del Estado Islámico no están locos ni son imbéciles". Entrevista a Phillippe-Josheo Salazar". El Mundo, 9 de diciembre de 2015. http://www.elmundo.es/internacional/2015/12/09/566712ece2704eb21f8b457a.html.

Zecca, Alfredo H. "«Ex corde ecclesiae»: una lectura a 20 años de su promulgación”. Humanitas - Pontificia Universidad Católica de Chile - Revista de Antropología y Cultura Cristiana. Accedido 6 de noviembre de 2015. https://tinyurl.com/y3q8dhhs

Fernando Viñado Oteo Facultad de Derecho, Empresa y Gobierno

Universidad Francisco de Vitoria Carretera Pozuelo a Majadahonda, Km 1.800, 28223

Pozuelo de Alarcón, Madrid (España) https://orcid.org/0000-0003-2178-1750

Ángel J. Barahona Plaza Facultad de Ciencias Experimentales Universidad Francisco de Vitoria Carretera Pozuelo a Majadahonda, Km 1.800, 28223

Pozuelo de Alarcón, Madrid (España) https://orcid.org/0000-0002-8378-4597 